\title{
SYNTHESIS OF FURFURAL FROM BAGASSE
}

\author{
Hayelom Gebre, Kiros Fisha, Tsegalaul Kindeya, Tsigehiwot Gebremichal \\ Department of Chemical Engineering, Adama Science and Technology University, Adama, \\ Ethiopia \\ Email address: ktsegish@gmail.com (T.Kindeya)
}

Keywords: Bagasse, Furfural, Furfuraldehyde, and Pentosans.

\begin{abstract}
Bagasse is a waste product from the sugar industry, which is usually used as energy source in factory at present. However, the amount of bagasse left is still high enough for more value-added product for example furfural. Bagasse is a good source of pentosan and containing about 25 to $27 \%$. The main objective of the research was to produce furfural from bagasse. The main raw material for the production furfural was bagasse and some chemicals/ingredients were used $\left(\mathrm{H}_{2} \mathrm{SO}_{4}\right.$, water, $\left.\mathrm{NaCl}\right)$. Furfural is an important organic chemical, produced from agro industrial wastes and residues containing carbohydrates known as Pentosans. It is a basic chemical, which can be utilized in a variety of industries such as chemical industry, refining oil industry, food industry and agricultural industry. In its pure state, it is a colourless or yellow oily liquid with the odour of almonds, but upon exposure to air it quickly becomes yellow then brown and finally black, it is commonly known as furfuraldehyde.
\end{abstract}

\section{INTRODUCTION}

Bagasse is a waste product from the sugar industry, which is usually used as energy source in factory at present. However, the amount of bagasse left is still high enough for more value-added products. It also, used as forage and raw material for production of pulp, paper making and particleboard. It has been reported that bagasse contains pentosan with concentration of 250-270 $\mathrm{g} / \mathrm{kg}$ of the original bagasse, which mainly consists of arabinoxylan (F. Currasco and C. Roy, 1992). Furfural is an important organic chemical, produced from agro industrial wastes and residues containing carbohydrates known as Pentosans. It is a basic chemical, which can be utilized in a variety of industries such as chemical industry, refining oil industry, food industry and agricultural industry. (H. D. Mansilla, J. Baezu, 1998)

Furfural was first isolated in 1821 (published in 1832) by the German chemist Johann Wolfgang Döbereiner, who produced a small sample as a byproduct of formic acid synthesis. At the time, formic acid was formed by the distillation of dead ants, and Döbereiner's ant bodies probably contained some plant matter. In 1840, the Scottish chemist John Stenhouse found that the same chemical could be produced by distilling a wide variety of crop materials, including corn, oats, bran, and sawdust, with aqueous sulfuric acid, and he determined the empirical formula $\left(\mathrm{C}_{5} \mathrm{H}_{4} \mathrm{O}_{2}\right)$. In 1901, the German chemist Carl Harries deduced furfural's structure (From Wikipedia, the free encyclopedia).

Now days, it is also usually produced from agricultural wastes containing pentosan as the main component, such as, rice straw, Bagasse and rice hull (H. D. Mansilla, J. Baezu, 1998).

One of the application bagasse is the production of a valuable material called furfural. This material is used in synthesis and production of various chemical compounds. Furfural has applications as a selective solvent in the refining of petroleum, lubricating oils, diesel fuels and vegetable oils. In the refining of lubricating oils, petroleum and diesel fuel, furfural has been used to separate aromatics and retain paraffinic-type compounds from the mixture to improve the viscosity index, ignition characteristics, oxidation stability, color, flash point, and to lower the carbon-forming tendency. It can also be used as the raw material for other by-products such as alcohol furfural and eruptions, 
which is the raw material for the production of many industrial resins. Moreover, the waste, after processing, is used as a light rich fertilizer.

Every year, a large amount of waste is created throughout the processing of sugar canes (Bagasse). Collection and disposal of these wastes is not only very costly and causes an excessive amount of environmental pollution, but also it is a great loss of wealth that can be used in different industries. Since the main raw material, bagasse is easily found from those industries we are initiated to produce an important organic chemical, furfural that is used in a variety of industries such as chemical industry, refining oil industry, food industry and agricultural industry.

The general objective of the research was to produce furfural from bagasse. And the specific objectives of the research was develop the Stoichiometry the raw materials of the feed to produce desired product, understand the properties and advantages of furfural, and regulate as well as control process parameters (temperature versus time).

\section{LITERATURE REVIEW}

\subsection{Sugar Cane}

Sugarcane is one of several species of tall perennial true grasses of the genus Saccharum, tribe Andropogoneae, native to the warm temperate to tropical regions of South Asia, and used for sugar production. They have stout jointed fibrous stalks that are rich in sugar, and measure two to six meters (6 to 19 feet) tall. All sugar cane species interbreed and the major commercial cultivars are complex hybrids. Sugarcane belongs to the grass family (Poaceae), an economically important seed plant family that includes maize, wheat, rice, and sorghum and many forage crops.

The main product of sugarcane is sucrose, which accumulates in the stalk internodes. Sucrose, extracted and purified in specialized mill factories, is used as raw material in human food industries or is fermented to produce ethanol. Ethanol is produced on a large scale by the Brazilian sugarcane industry. Sugarcane is the world's largest crop. (Crop production, 2010) It is a grass that forms lateral shoots at the base to produce multiple stems, typically about five $\mathrm{cm}$ in diameter. The stems grow into cane stalk, which when mature constitutes approximately $75 \%$ of the entire plant. A mature stalk is typically composed of $11-16 \%$ fiber, $12-16 \%$ soluble sugars, $2-3 \%$ non-sugars, and $63-73 \%$ water. A sugarcane crop is sensitive to the climate, soil type, irrigation, fertilizers, insects, disease control, varieties, and the harvest period. The average yield of cane stalk is 60-70 tonnes per hectare yearly that is also used as livestock fodder. It is harvested by hand and mechanically. Hand harvesting accounts for more than half of production, and is dominant in the developing world (Rena and Perez, 1997).

Sugarcane is a major crop in many countries. It is one of the plants with the highest bio-conversion efficiency. Sugarcane crop is able to efficiently fix solar energy, yielding some 55 tonnes of dry matter per hectare of land annually. Sugarcane processing produces cane sugar (sucrose) from sugarcane. Other products of the processing include molasses, filter cake and bagasse.

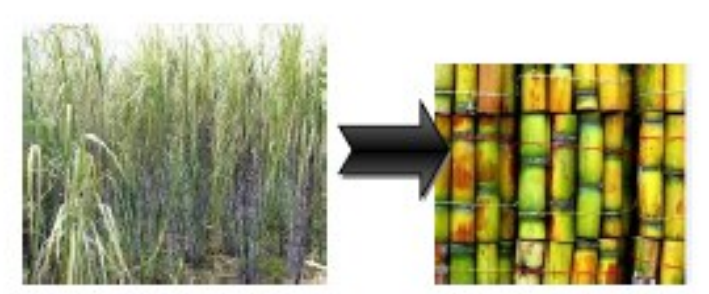

Figure 2.1 Sugar cane 


\section{Molasses}

It is produced in two forms: Blackstrap, which has a characteristic strong flavor because of its vitamin and mineral content, and purer molasses syrup. Blackstrap molasses is sold as a food and dietary supplement. It is also a common ingredient in animal feed, is used to produce ethanol and rum, and in the manufacturing of citric acid. Purer molasses syrups are sold as molasses, and may also be blended with maple syrup, invert sugars, or corn syrup. Both forms of molasses are used in baking.

\section{Filter cake}

Filter cake is obtained when the cane juice is clarified using calcium hydroxide, contains material originally suspended in the juice along with inorganic salts that precipitate during the clarification process. In agriculture, filter cake is used as a fertilizer, and is applied directly or indirectly (as compost) on the sugarcane fields. It is also used as an animal feed supplement.

\subsection{Bagasse}

The residue of cane after juice extraction, known as bagasse is the most common fuel used in cane sugar manufacture. The proportion of bagasse produced per 100 tonnes of cane crushed varies from 25 to 32 , usually lying around $27-28 \%$. The fresh mill bagasse contains $48-50 \%$ water, $2.5-3.5 \%$ dissolved solids or brix and $46-48 \%$ fibre. The brix or the dissolved solid in bagasse has its origin in the cane juice while the fibre constitutes the insoluble cellulosic matter of sugar cane.

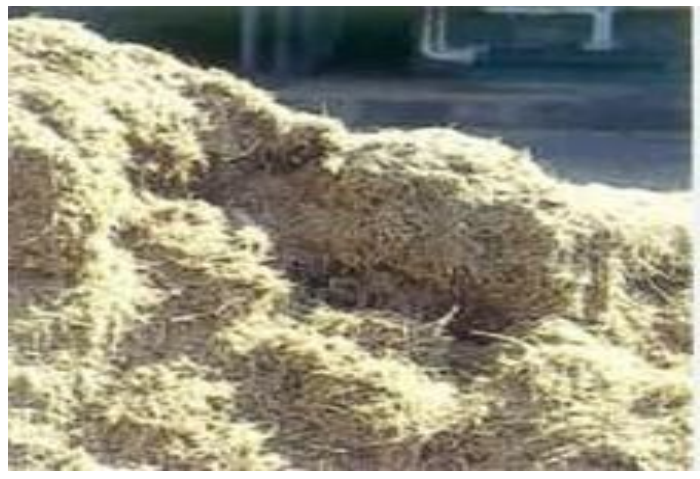

Figure 2.2 Bagasse

Some of the applications of bagasse are:

$>$ As fuel for the boilers and kilns

$>$ For production of paper, paperboard products and reconstituted panel board

$>$ For agricultural mulch, and

$>$ As a raw material for production of chemicals such as furfural

The primary use of bagasse is as a fuel source for the boilers in the generation of process steam in sugar plants (Sugarcane processing, 2005.)

\subsection{Furfural}

Furfural is a liquid chemical that is sourced from renewable resources-it is created from the hemicellulose components (pentosans) of vegetable matter. It is also the only compound of the furan series being directly obtained from biomass (e.g. bagasse) at industrial scale. Furfural production is generally carried out by hydrolysis of hemicelluloses-derived pentosans into monomeric pentoses, and their subsequent acid-catalyzed dehydration. In its pure state, it is a colorless or yellow oily liquid with the odor of almonds, but upon exposure to air it quickly becomes yellow then brown and finally black, it is commonly known as furfuraldehyde. It is an important organic chemical, produced from agro industrial wastes and residues containing carbohydrates known as Pentosans. As no commercial synthetic routes have been found so far, all furfural manufacturing activity is 
based on pentosan containing residues that are obtained from the processing of various agricultural and forest products. In commercial terms, the most important intermediate derived from furfural is furfuryl alcohol.

Furfural is a hazardous chemical, being both toxic and flammable. Fortunately, incidents involving furfural are very rare, which is probably due to its low volatility; it has a boiling point of $161 \mathrm{oc}$. In small doses furfural is not a problem and we all have a little furfural each day in our food and drink. It occurs naturally in nectarines and sweet potatoes. It is imparted to wines and spirits by maturing in wood and is created by high temperature cooking processes such as baking, roasting, frying and grilling. The chemical formula for furfural is $\mathrm{C}_{5} \mathrm{H}_{4} \mathrm{O}_{2}$, in structure it is a heterocyclic compound consisting of a furan ring (four carbon atoms and an oxygen atom) plus an aldehyde group shown in fig 2.3. The furan ring is common in nature, being a component of the sucrose molecule.

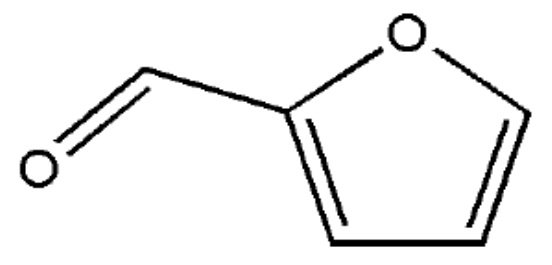

Figure 2.3 Structure of Furfural

Furfural is only partially soluble in water and with a density of $1160 \mathrm{~kg} / \mathrm{m}^{3}$, therefore when separation occurs the water layer is on the top. At $20^{\circ} \mathrm{C}$ the furfural layer contains $5 \mathrm{wt} \%$ water while the water layer contains $8.3 \mathrm{wt} \%$ furfural. During distillation of furfural/water mixtures a low boiling azeotrope is formed. The azeotrope contains $35 \%$ furfural and boils at $97.85{ }^{\circ} \mathrm{C}$ (at atmospheric pressure) (Lj Watson, 2010).

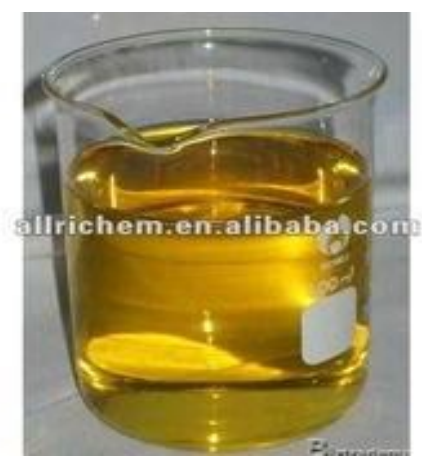

Figure 2.4 Furfural

Furfural's physical properties are summarized in the table below. Furfural dissolves readily in most polar organic solvents, but is only slightly soluble in either water or alkanes.

Chemically, furfural participates in the same kinds of reactions as aldehyde and other aromatic compounds. Indicating its diminished aromaticity relative to benzene, furfural is readily hydrogenated to the corresponding tetrahydrofuran derivatives. When heated above $250{ }^{\circ} \mathrm{C}$, furfural decomposes into furan and carbon monoxide, sometimes explosively. When heated in the presence of acids, furfural irreversibly solidifies into a hard thermosetting resin. 
Table 1.1 Physical properties of furfural

\begin{tabular}{|l|l|}
\hline & \multicolumn{2}{|c|}{ Properties } \\
\hline Molecular formula & $\mathrm{C}_{3} \mathrm{H}_{4} \mathrm{O}_{2}$ \\
\hline Molar mass & $96.08 \mathrm{~g} \mathrm{~mol}$ \\
\hline Appearance & Colorless oil \\
\hline Odor & Almond-like \\
\hline Density & $1.16 \mathrm{~g} / \mathrm{mL}\left(20^{\circ} \mathrm{C}\right)$ \\
\hline Melting point & $-37^{\circ} \mathrm{C} ;-35^{\circ} \mathrm{F} ; 236 \mathrm{~K}$ \\
\hline Boiling point & $162^{\circ} \mathrm{C} ; 324^{\circ} \mathrm{F} ; 435 \mathrm{~K}$ \\
\hline Solubility in water & $83 \mathrm{~g} /$ \\
\hline Acidity & $0.08-1 \mathrm{~mol} / 1$ \\
\hline
\end{tabular}

(Source: From Wikipedia, the free encyclopedia)

\subsubsection{Pentosan content of various raw materials}

The production of furfural requires raw materials rich in pentosan. The pentosan content of some material is given in table 2 .

Table 2.2 The pentosan content of various raw materials in percent of dry mass

\begin{tabular}{|l|l|}
\hline Raw material & Pentosan content (\%) \\
\hline Corn cobs & 30 to 32 \\
\hline Oat hulls & 29 to 32 \\
\hline Almond husks & 30 \\
\hline Cottonseed hull bran & 27 to 30 \\
\hline Birch wood & 27 \\
\hline Bagasse & 25 to 27 \\
\hline Sun flower husks & 25 \\
\hline Beech wood & 24 \\
\hline Flax shives & 23 \\
\hline Hazelnut shells & 23 \\
\hline Residues of olive extraction & 21 to 23 \\
\hline Eucaplatus wood & 20 \\
\hline Quebracho wood after tannin extraction & 19 \\
\hline Balsa wood & 18 \\
\hline Rice hulls & 16 to 18 \\
\hline Spruce wood & 11 \\
\hline Pine wood & 7 to 9 \\
\hline Douglas fir wood & 6 \\
\hline
\end{tabular}

The pentosan content is measured by converting the pentosan to furfural, and by then determining the furfural, usually by precipitation with barbituric acid (The Australian sugar industry Vol 30, 2008). 


\subsubsection{The reaction leading to furfural}

Furfural is universally made from agricultural raw material rich in pentosan. By aqueous acid catalysis, the pentosan is hydrolyzed to pentose, and this pentose is dehydrated to furfural in a unified process (Zeitch, 2000).

\subsubsection{Stoichiometry}

The Stoichiometry of the two reactions reads as follows:

(1) Hydrolysis of pentosan:

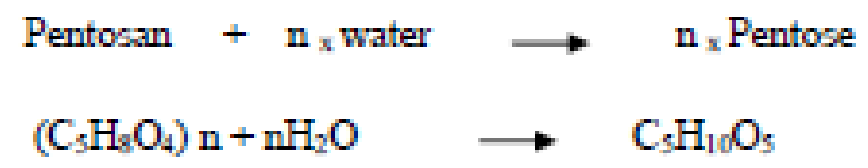

(2) Dehydration of pentose

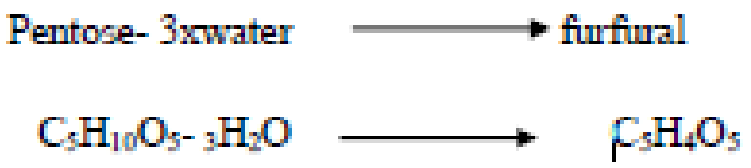

Thus over all reaction can said to be

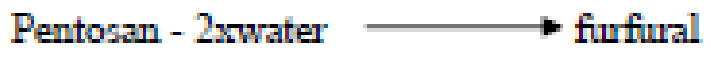

\subsubsection{Mechanisms}

Pentosan consists of predominantly rings linked by oxygen bridges as shown<smiles>COc1cc(C(C)(C)C)oc1OC</smiles>

Figure 2.5 Structure of Pentosan

The mechanism of the acid hydrolysis of pentosan is comprise in the following steps

1. Protonation of an oxygen link, thus leading to trivalent oxygen.

2. Cleavage of a carbon/oxygen bond leading to a carbon onside of the oxygen bridge, and to a hydroxyle group on the other side of the oxygen bridge.

3. The carocation takes up water.

4. The resulting $\mathrm{H}_{2} \mathrm{O}^{+}$group liberates a hydrogen ion, thus leading a hydroxyl group behind.

This sequence of process is repeated until all oxygen bridge has dispersed so that the rings have become individual pentose molecules (Zeitch, 2000).

\subsubsection{Acid catalysis}

As we stated in the above the hydrolysis of pentosan to pentose and dehydration of pentose to furfural are both catalyzed by acids. It is therefore; appropriate to give a brief summary of important features of acid catalysis (Zeitch, 2000). 


\subsubsection{The temperature dependence of acidity}

In the second half of the nineteenth century, svante Arrhenius (1859-1927) found the rate of acid catalyzed reactions to be proportional to the hydrogen ion concentration. Although it turned out later that this is only special case of a more general proton transfer concept, the hydrogen ion concentration remains an important aspect in acid catalysis.

\subsection{Furfural production steps}

i. Drying

Dryer is the first equipment in the furfural production which is used to remove the moister content of the bagasse from $45 \%$ to $15 \%$ at a temperature of $100 \mathrm{oC}$.

\section{ii. Grinding}

The dried bagasse is then entering to the grinding unit in order to grind the bagasse /in order to decrease its size.

iii. Sieving

It is used to sieve the crushed bagasse to the particle size of 30 to $40 \mathrm{~mm}$ (i.e. to remove course or larger materials and bagasse).

\section{iv. Reactors}

Furfural is made from the pentosan contained in the fiber. The method consists of pressure cooking the fiber (bagasse) in the presence of acid. During the initial heating the solid pentosan reacts with water to form soluble pentose, when the temperature rises above $165{ }^{0} \mathrm{C}$ the pentose undergoes a dehydration reaction to yield furfural. There are three types of digesters for the commercial production of furfural at the present time. These are described below.

\section{$>$ Quaker batch process}

The initial production process was developed by Quaker Oats at their Cedar Rapids plant. Though Quaker no longer produces furfural, their process continues in a number of plants including the largest at Central Romana. It is a batch process where the feedstock is mixed with sulphuric acid and then reacted in a rotating spherical digestor (up to $6 \mathrm{~m}$ in diameter) at $153{ }^{\circ} \mathrm{C}(515 \mathrm{kPag}$ ) while being sparged with superheated steam (Zeitsch, 2000). As furfural is formed it is stripped off by the steam passing through the bed. After 5 hours the process is stopped and the residue is emptied from the digestors. It consists of the cellulose and lignin fractions and in many cases is used as fuel. The steam and furfural vapors extracted from the digestor are condensed and then separated using decanting and distillation.

\section{Chinese batch process}

The Chinese process differs from the Quaker batch process in that the digestors do not rotate. They consist of large cylinders in which steam, at 5 bars, is passed through a static bed $1.5 \mathrm{~m}$ diameter and $8 \mathrm{~m}$ tall. Percolation of steam through the bed is assisted by ensuring that the size of the corn cobs is between 20 to $30 \mathrm{~mm}$ (Zeitsch, 2000).

\section{Rosenlew continuous process}

The Rosenlew process is similar to the Chinese process in that vertical digestors are used however they are operated in a continuous fashion. The only Rosenlew plant operating at present uses sifted bagasse as the feedstock. The coarse fraction is admitted to the top of the digestors via a lock hopper and residue is discharged from the bottom through valves. Steam at 10 bars is fed into the bottom and flows upwards through the bagasse. Unlike other processes, sulphuric acid is not added to assist furfural production; instead, organic acids formed by side reactions concentrate within zones of the digestor and promote furfural production. Steam and furfural leave from the top of the digestor (Zeitsch, 2000). 


\section{v. Distillation of furfural}

All furfural reactors known so far to produce a vapor stream consisting of more than $90 \%$ water of up to $6 \%$ frufural and various by product. After liquefaction, commonly used to make secondary steam, and sometimes after a filtration or a centrifugal separation of solids, the products stream is fed in to an azeotrope distillation.

A typical simple distillation plant is, used to make of the water/furfural azeotrope boiling point of $97.850 \mathrm{c}$ and a water content of $65 \%$. The Column is commonly called the azeotrope column although this is unfortunate as in a subsequent column the same azeotrope is used for the dehydration of furfural, so that the attribute is not a unique feature of the column.

The sump fraction of the column is water loaded with some carboxylic acid, mostly acetic acid. This fraction is sometimes discharged in to the sea or in to waste water treatment plant.

\section{vi. Decanters}

From the azeotrope column, commonly a tray column fraction roughly corresponding to the azeotrope is withdrawn as a liquid side stream and fed into decanter where it separate the liquid phase, a light phase rich in water, and a heavy phase rich in furfural . The light phase is reflex in to the azeotrope column. The heavy phase of decanter consists typically of $94 \%$ frufural. It is passed through a neutralizer and then fed in to a randomly packed vacuum 5 energized by a reboiler as well as steam injection where the raw furfural from the neutralizer.

\section{vii. Neutralizers}

The furfural from the decanter is passed through a neutralizer in order to neutralize the acidic media by adding $\mathrm{NaOH}$ and then fed in to a randomly packed vacuum energized by a reboiler as well as steam injection where the raw furfural and polymer are separated from the neutralizer.

Generally the production process of furfural is summarized as shown in the block diagram bellow. 


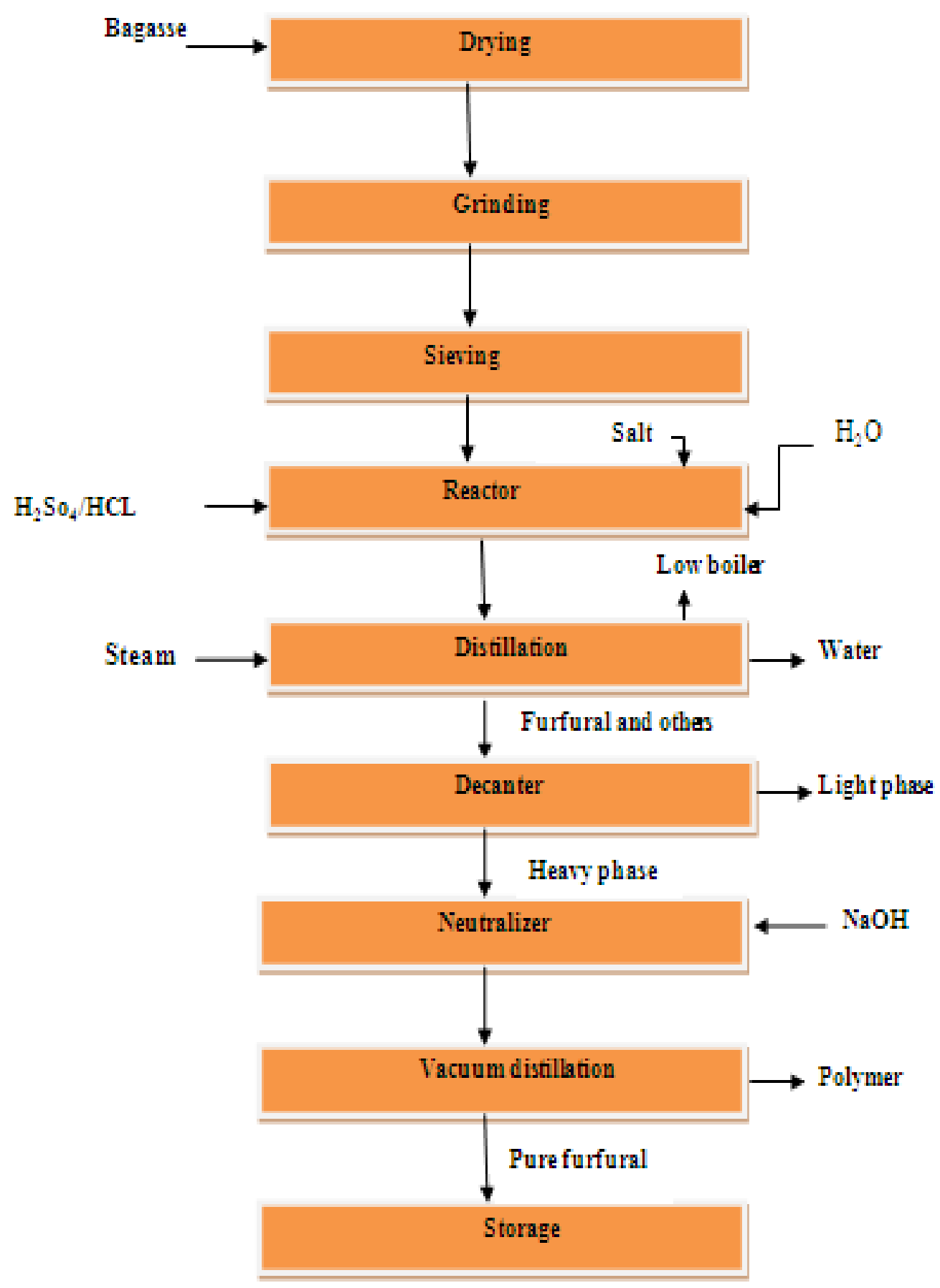

Figure 2.6 Block diagram of furfural production process

\section{MATERIALS AND METHODS}

The experiments of production of furfural from bagasse were carried out in the laboratory of Chemical Engineering Department at Adama science and Technology University.

\subsection{Materials Use for the Experiments}

The main raw material for the production of furfural is,

- Bagasse

Chemicals that are used for the experiment are,

- Sulfuric acid $\left(\mathrm{H}_{2} \mathrm{SO}_{4}\right)$ : used as catalysts.

- Water :to dissolve the pentose

- Salt $(\mathrm{NaCl})$ : enhancing the furfural selectivity and rate of formation. 
Main equipment's for furfural production

- Grinder: to grind the bagasse.

- Sieve: to sieve the crushed sample to the particle size of $1 \mathrm{~mm}$

- Round bottom flask: as batch reactor for the solution

- Tube and condenser: to collect and cool the product

- Beaker: to store product.

- Shaker(stirrer): to shake sample

- Measuring cylinder: to dilute the concentrated acid

- Burette: for measuring the volume of the water and sulfuric acid

- Thermometer: Device to measure temperature.

- Oil bath: Device to boil the sample.

\subsection{Experimental Procedure}

In a $500 \mathrm{ml}$. round-bottomed flask are placed $0.015 \mathrm{~kg}$ of dry bagasse (ground to about the size of $1 \mathrm{~mm}$ ) $150 \mathrm{ml}$ diluted sulfuric acid, and $0.005 \mathrm{~kg}$ of salt. The flask is shaken in order to secure a homogeneous mixture and is then connected with tube, water condenser, shown in Fig3.1. Heat is applied from the oil bath, the flame being adjusted so that the liquid distils at a rapid rate. The distillation process is continued until practically no more furfural can be seen collecting in the distilling flask used as a receiver. The above operation requires 40 minutes. This experiment repeats 3 times at different temperatures, sample amounts (bagasse) and salt.
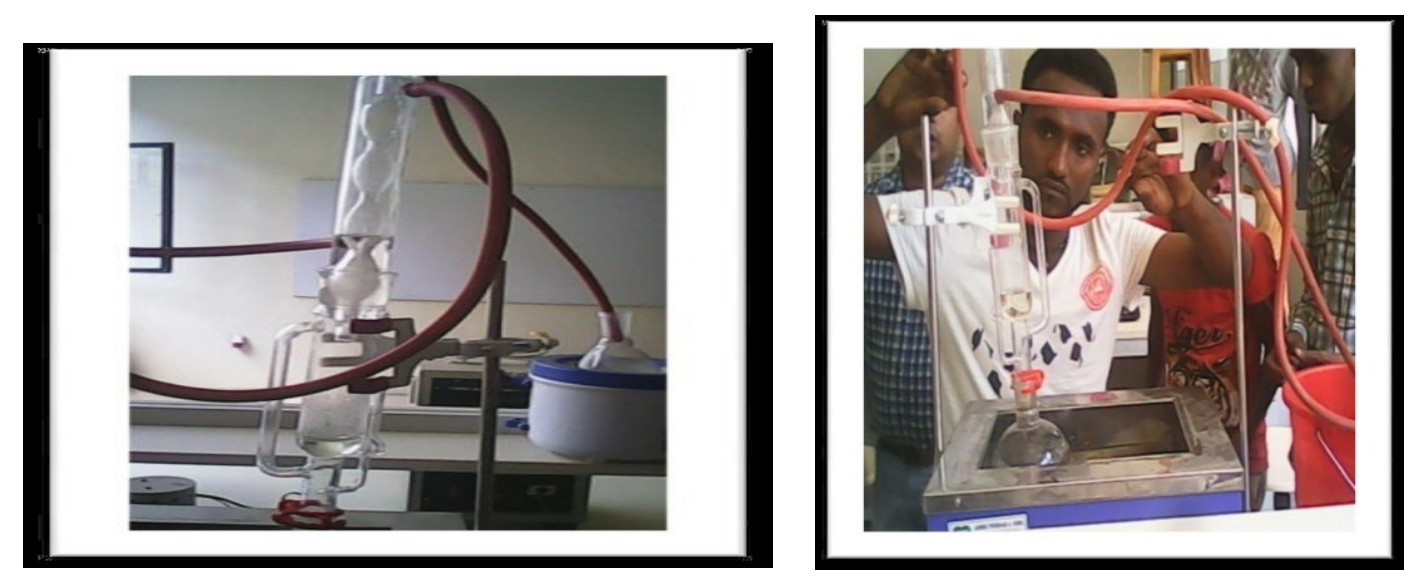

Figure 3.1 Experimental set up for furfural synthesis

\section{RESULT AND DISCUSSION}

Table 4.1 Parameter for the experiment at different temperature

\begin{tabular}{|c|c|c|c|}
\hline № of Sample & 1 & 2 & 3 \\
\hline Mass of sample (bagasse) (g) & 15 & 10 & 10 \\
\hline Mass of sample(salt) (g) & 5 & 10 & 7 \\
\hline Amount of diluted acid (ml) & 150 & 100 & 100 \\
\hline Temperature ("c) & 170 & 200 & 190 \\
\hline Time (min) & 40 & 40 & 40 \\
\hline Mass of beaker(m) & 187.1 & 101.5 & 101.5 \\
\hline $\begin{array}{l}\text { Mass of product }\left(m_{2}\right)+\text { mass of } \\
\operatorname{beaker}(g)\end{array}$ & 211.6 & 132.3 & 129.2 \\
\hline Mass of product $\left(\mathrm{m}_{2}-\mathrm{m}_{1}\right)$ & 24.5 & 30.8 & 27.7 \\
\hline
\end{tabular}




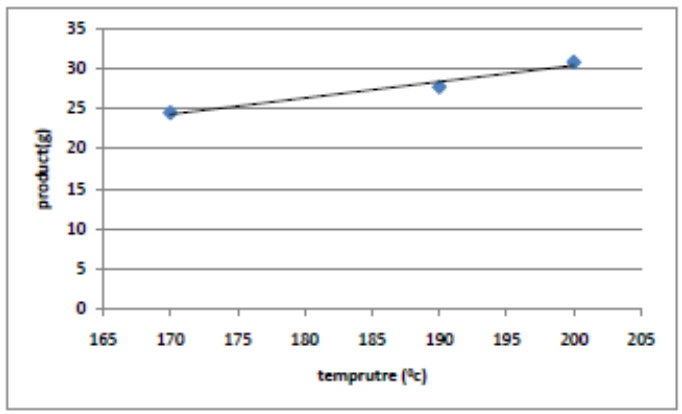

Figure 4.1 Product verses temperature graph

\subsection{Effect of temperature on the product}

From the experiment we observed that as the temperature increases the amount of the product which is (furfural, water and others) increases and also observed that the color was yellow which indicates one of the characteristics of the furfural.

\subsection{Effect of salt on the product}

The salt has a positive effect on enhancing the rate of formation of furfural so that from the result that indicates in the table an increasing the amount of the salt it also increase the product and a color change was observed.

\subsection{PH}

$\mathrm{PH}$ is the one that measure acidity, base characteristics of solution. Therefore, the $\mathrm{PH}$ of the products that was measured in the laboratory was $1.8,0.5$ and 1.23 respectively. From the result we observed that the acidity increases with the product. I.e. the increasing the acidity of the product indicates that amount of furfural is high in the product.

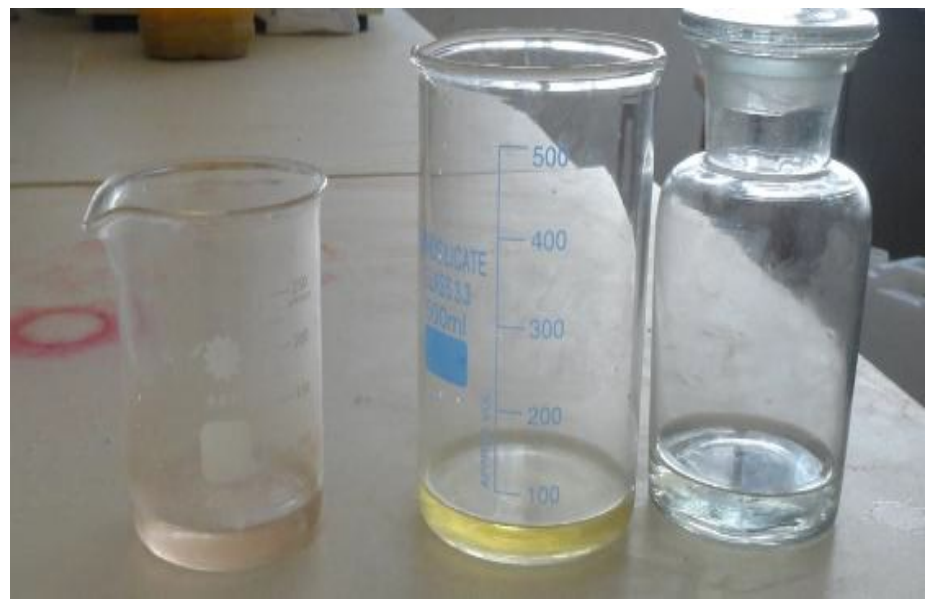

Figure 4.2 Furfural (product)

\section{CONCLUSION AND RECOMMENDATION}

\subsection{Conclusion}

The study was aimed at synthesis of furfural from bagasse. The type of ingredients which are suitable for furfural synthesis specified in the experimental part during production process and what are the procedures to be considered and which order is come first for good final quality product were considered. From the experiment the yields of furfural depend on the temperature and amount of salt because, salt has great effect on furfural formation. Many new developments would takes place in acid hydrolysis process and use of furfural for many applications such as for synthesizing a family of derived solvents like furfuryl alcohol and tetrahydrofuran and in the production of resins 
for molded plastic and metal coatings. Furthermore, it plays a big role in the manufacture of insecticide as well. Recently, furfural has been used in the food industry for flavoring purpose too.

\subsection{Recommendations}

Based on the gaps identified in this research work, the following recommendations are made for the future researchers to bring integrated and valuable knowledge contributions to the country.

$>$ Further researches have to be done to improve the production of high quality and quantity of furfural from bagasse.

$>$ Alternative extraction methods of furfural such as diluted hydrochloric acid extraction have to be done in order to investigate the variation that could be arise on the quality and quantity of the furfural yield.

Extraction parameters such as time, temperature, and others shall be optimized in detail.

\section{Acknowledgement}

First, we would like to thank full our advisor Dr. RAJU MALIGER for his unstopped advice and assistance to accomplish this project successfully. Secondly thanks to those who provided us basic information and for their cooperation in our duty especially for Wonji Sugar Factory.

\section{Reference}

[1] Corma, O. de la Torre, M. Renz, and N. Villandier. Production of high quality diesel from biomass waste products. Angew. Chem. Int. Ed., 50:1-5, 2011.

[2] De Lucas, L. Rodriguez, P. Sanchez, and A. Carnicer. Extraction of aromatic compounds from heavy neutral distillate lubricating oils by using furfural. Separ. Sci. Tech., 28:24652477, 1993.

[3] Gandini. The irruption of polymers from renewable resources on the scene of macromolecular science and technology Green Chem., 13:1061 1083, 2011.

[4] P.Dunlop and F. N. Peters. The Furans. ACS Monograph Series. Reinhold Publishing Corporation, New York, 1953.

[5] Crop production". Food and Agriculture Organization of the United Nations. Retrieved 2010

[6] D.F. Aycock. Solvent applications of 2-Methyltetrahydrofuran in organo metallic and biphasic reactions. Org. Process Res. Dev.11:156-159, 2007.

[7] Dalin Yebo Trading \&Development Pty Ltd, www.dalinyebo.co.za/dalinyebo-tradingdevelopment-pty-ltd. Personal communication, 2011

[8] E. de Jong. XYX Building blocks: Biorefinery Approach towards Fuels and Plastic Applications. In World Biofuel Markets, Rotterdam, March 2011

[9] Food and Agriculture Organization Statistics - FAOSTAT. Available at http://faostat.fao.org

[10] G. Collin, R. Mildenberg, M. Zander, H. Höke, W. McKillip, W. Freitag, and W. Imöhl. Resins, synthetic In Ullmann's Encyclopedia of Industrial Chemistry. Wiley-VCH Verlag GmbH \& Co. KGaA, 2000.

[11] G.W. Huber, J.N. Chheda, C. J. Barrett, and J.A. Dumesic. NProduction of liquid alkanes by aqueous-phase processing of biomass-derived carbohydrates. Science, 308:1446-1450, 2005

[12] G.W. Huber, S. Iborra, and A. Corma. Synthesis of transportation fuels from biomass: Chemistry, catalysts, and engineering. Chem. Rev., 106:4044- 4098, 2006

[13] H. E. Hoydonckx, W. M. Van Rhijn, W. Van Rhijn, D. E. De Vos, and P. A. Ja- cobs. Furfural and derivatives. In Ullmann's Encyclopedia of Industrial Chemistry. Wiley-VCH Verlag GmbH \& Co. KGaA, 2000 
[14] H. Müller. Tetrahydrofuran. In Ullmann's Encyclopedia of Industrial Chem istry. Wiley-VCH Verlag GmbH \& Co. KGaA, 2005

[15] J. Lessard, J.-F. Morin, J.-F. Wehrung, D. Magnin, and E. Chornet. High yield conversion of residual pentoses into furfural via zeolite catalysis and catalytic hydrogenation of furfural to 2-methylfuran Top. Catal., 53:1231-1234, 2010

[16] K. J. Zeitsch. The chemistry and technology of furfural and its many by-products, volume 13 of Sugar Series. Elsevier, 2000

[17] L.C. Kemp, G.B. Hamilton and H.H. Gross. Furfural as a selective sol vent in petroleum refining. Ind. Eng. Chem., 40:220-227, 1948

[18] L. Petrus and M.A. Noordermeer. Biomass to biofuels, a chemical perspec tive. Green Chem , 2006

[19] M. Chours, M. N. Belgacem, and A. Gandini, Acid-catalyzed polycondensation of furfuryl alcohol: mechanisms of chromophore formation and cross-linking. Macromolecules, 29:3839-3850, 1996

[20] Rena Perez (1997). "Feeding pigs in the tropics". Food and Agriculture Organization of the United Nations.

[21] R. Rodríguez-Kábana, J.W. Kloepper, C.F. Weaver, and D.G. Robertson. Control of plantparasitic nematodes with furfural- A naturally occurring fumigant. Nematropica, 23:63-73, 1993.

[22] S. Bayan and E. Beati. Il furfurolo ed i suoi derivati come carburanti. Cim. Ind. (in Italian), 23:432-434, 1941

[23] S. Lande, M. Eikenes, M. Westin, and M. Schneider. Furfurylation of wood:Chemistry, properties, and commercialization. In T.P. Schultz, M. Militz, M.H. Freeman, B. Goodell, and D.D. Nicholas, editors, Development of Commercial Wood Preservatives, number 982 in ASC symposium series, pages 337-355. American Chemical Society, 2008

[24] S. Lande, M. Westin, and M. Schneider. Development of modified wood products based on furan chemistry .Mol.Cryst. Liq Cryst., 484:367-378, 2008

[25] S. Lande, O. Høibø, and E. Larnøy. Variation in treatability of Scots pine (pinus sylvestris) by the chemical modification agent furfuryl alcohol dissolved in water. Wood Sci. Technol., 44:105-118, 2010

[26] Sugarcane processing". Environmental Protection Agency, United States. 2005.

[27] Wikipedia, the free encyclopedia

[28] Y Kar and H Deveci. Importance of P-series fuels for flexible-fuel vehicles (FFVs) and alternative fuels. Energ. Source., 28(9-12):909-921, 2006 